\title{
Modelo de monitoreo geológico-geotécnico mediante convergencias para definir el sostenimiento final de un túnel con fines civiles y mineros - túnel de conducción de la Central Hidroeléctrica Cheves
}

\author{
Geological-geotechnical monitoring model using convergences to define the \\ final support of a tunnel for civil and mining purposes - conduction tunnel of \\ the Cheves Hydroelectric Power Plant
}

Richard Eduardo Ángeles Bazán 1

Recibido: 01/03/2021 - Aprobado: 20/07/2021 - Publicado: 23/12/2021

\begin{abstract}
RESUMEN
La investigación analiza el resultado que se obtuvo de aplicar el modelo de monitoreo geotécnico mediante convergencias, la cual definió el sostenimiento final del túnel de conducción de la central Hidroeléctrica Cheves, esta central hidroeléctrica está ubicada en el distrito de Churín, provincia de Oyón, departamento de Lima. El túnel de conducción consta de 9693 metros de longitud; el proceso de excavación subterránea se realizó teniendo en cuenta el Nuevo Método Austriaco de Construcción de Túneles, el cual se define como un método que integra los principios del comportamiento de masas rocosas sometidas a cargas y la monitorización de la eficiencia de la construcción bajo tierra. En la excavación subterránea se intercepta el contacto Geológico entre el Grupo Casma y la Formación Chimú, que fue afectado por el evento del post Intrusivo Churín, que aumento las zonas de debilidad en la Formación Casma, como fallas geológicas rellenas de minerales expansivos que están buzando al interior del eje del túnel. El sostenimiento inicial del túnel de conducción fue definido después de haber evaluado mediante clasificación geomecánica; posteriormente en los tramos donde se evidenció intensidad de fracturamiento, los cuales repercutieron en el sostenimiento inicial instalado, originadas en rocas blandas que integran el macizo rocoso, se instalaron estaciones de convergencias, con el fin de monitorear la deformación en tiempo y espacio del sostenimiento instalado, aplicando así el modelo de monitoreo geotécnico. En consecuencia, se tuvo como objetivo analizar el resultado de aplicar el modelo de monitoreo geotécnico en el túnel de conducción, excavación subterránea, de la central hidroeléctrica Cheves- Churín; la cual sirvió para definir y corroborar la estabilidad del túnel de conducción, relacionado al sostenimiento aplicado en la excavación subterránea de dicho túnel.
\end{abstract}

Palabras claves: Monitoreo geológico; monitoreo geotécnico; convergencias; túnel de conducción; Central Hidroeléctrica Cheves.

\begin{abstract}
The research analyzes the results obtained from applying the geotechnical monitoring model through convergences in the conduction tunnel of the Cheves hydroelectric plant - located in the district of Churín, province of Oyón, department of Lima. The conduction tunnel is 9693 meters long; during the underground excavation process using the New Austrian Tunnel Construction Method, which integrates the principles of the behavior of rock masses subjected to loads and the monitoring of the efficiency of underground construction. In the underground excavation, the geological contact between the Casma Group and the Chimú Formation is intercepted, which was affected by the post Intrusive Churín event, which increased the areas of weakness in the Casma Formation, such as geological faults filled with expansive minerals that are dipping to the ground. inside the tunnel shaft. The initial support of the conduction tunnel was defined after having been evaluated by means of geomechanical classification; Subsequently, in the sections where the intensity of fracturing that originates soft rocks that make up the rocky massif was evidenced, convergence stations were installed, in order to monitor the deformation in time and space of the installed support, thus applying the geotechnical monitoring model. Consequently, the objective was to analyze the result of applying the geotechnical monitoring model in the conduction tunnel, underground excavation, of the Cheves-Churín hydroelectric plant, which served to define and corroborate the stability of the conduction tunnel, related to the support applied in the underground excavation of said tunnel.
\end{abstract}

Keywords: Geological monitoring; geotechnical monitoring; convergences; conduction tunnel; Cheves Hydroelectric Plant.

\footnotetext{
1 Universidad Nacional Mayor de San Marcos, Unidad de Posgrado, Lima, Perú. Egresado de Maestría de Geología - Mención Geotecnia. E-mail: eduardo 020405@hotmail.com - ORCID: https://orcid.org/0000-0001-7459-5383
} 


\section{INTRODUCCIÓN}

La Central Hidroeléctrica Cheves, incluye el túnel de conducción (frente de excavación denominado DR -04) que presenta una longitud de 9693 metros lineales, y el tramo final lo constituye el túnel de descarga (frente de excavación denominados DR-14 y DR-15) que consta de $3.20 \mathrm{Km}$, aparte de ello se excavó una caverna en la que se instaló una casa de máquinas en la cual se encuentran las dos turbinas Pelton, las que generan energía eléctrica, en el proceso constructivo se tuvo que excavar túneles de accesos y bypass que sirvieron para la construcción final de dicha hidroeléctrica.

En este trabajo analiza el resultado de aplicar el modelo de monitoreo geológico- geotécnico mediante convergencias, la cual concluye, que existe un determinado sostenimiento, que estabiliza una excavación subterránea, y que es producto de aplicar el monitoreo geológico - geotécnico mediante convergencias; se realiza este estudio, ya que dicho análisis hasta el momento no ha sido presentado. El túnel de conducción presenta una sección de excavación de tipo baúl. Para la evaluación geomecánica de los frentes de excavación del túnel de la Central Hidroeléctrica Cheves se utilizaron dos métodos de clasificación geomecánica: el RMR (Rock Mass Rating) propuesto por Bieniawski (1989) y el Sistema Q propuesto por Barton et al. (1974). En el tramo comprendido entre las progresivas $2+158.00$ a 2+180.00 del Túnel de Conducción (Frente de excavación DR- 04), al momento de la excavación se intercepto una falla geológica buzando al interior del eje del túnel, esta falla geológica se encontraba rellena de minerales expansivos. De la evaluación Geomecánica realizada in-situ al momento de la excavación subterranea, se obtuvieron valores promedios: según Clasificación RMR de 11 (Roca Tipo V) y según clasificación Q de Barton de 0.01 (roca extremadamente mala).

El modelo geotécnico aplicado en el túnel de conducción que se desarrolló en la central hidroeléctrica
Cheves- Churin consistió en instalar 108 estaciones de monitoreo geotécnico en distintos tramos del túnel de conducción, cada estación de monitoreo consta de tres hitos, un hito se ubica en el centro de la corona o bóveda los otros dos en el hastial derecho y hastial izquierdo respectivamente, con ello se mide la deformación o movimiento de la sección del sostenimiento del túnel. Los resultados de las medidas en las estaciones del monitoreo geotécnico de la progresiva Km 1+080 arrojaron valores de hasta $38.29 \mathrm{~mm}$ de diferencia acumulada, en la estación de monitoreo geotécnico de la progresiva $\mathrm{Km}$ $1+091$ se observó un valor de $38.28 \mathrm{~mm}$ de diferencia acumulada, y en la estación de monitoreo geotécnico de la progresiva km $1+121$ se observó el valor más alto de convergencias con $78.03 \mathrm{~mm}$ de diferencia cumulada. Se colocó un sostenimiento Inicial y un sostenimiento final, el sostenimiento final fue complejo debido a los altos valores que arrojaron las estaciones de monitoreo geológicogeotécnico.

\section{1. Área de Estudio}

La zona de investigación se ubica en "La vertiente del Océano Pacífico, en la cuenca del río Huaura, entre las localidades de Sayán y Churín". "Políticamente las obras y las áreas de concesión del Proyecto se ubican en la jurisdicción de los distritos de Paccho y Checras en la provincia de Huaura; y Naván, Andajes y Pachangara en la provincia de Oyón, del departamento de Lima". Su relieve es accidentado, debido a que el valle principal es bastante estrecho, además de tener pocas zonas planas. Esta zona forma parte de las cuencas de los ríos Huaura y Checras, con elevaciones que varían entre 2,185 y 2,350 metros sobre el nivel del mar. El túnel de conducción incluido en el "proyecto de la central hidroeléctrica Cheves", tiene una longitud de 9693 metros. La concesión de la central hidroeléctrica Cheves, tiene una superficie de 4390 hectáreas. En la figura 1 se indica la zona de influencia del proyecto Central Hidroeléctrica Chevez y la confluencia del río Churín, río Checras y el rio Huaura.

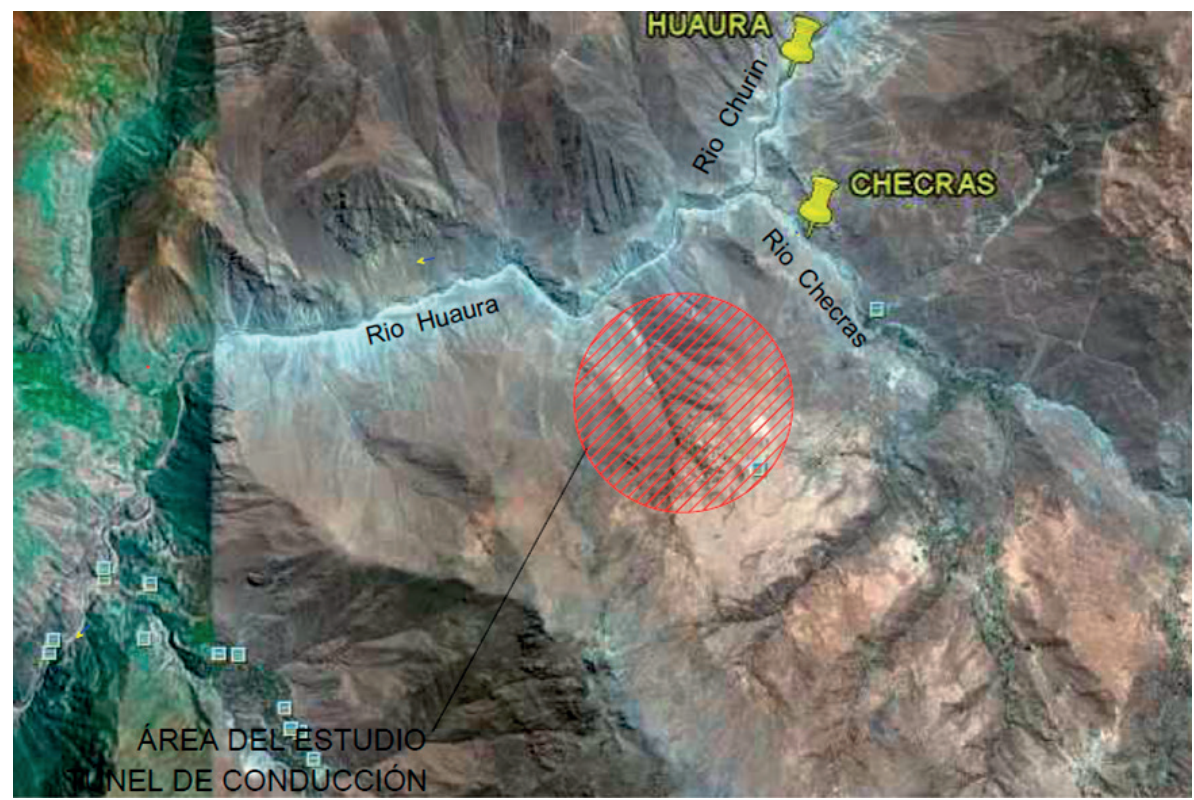

Figura 1. Área de Investigación (Cobbing, 1973) 


\section{MÉTODOS}

En este estudio se vio por conveniente incluir los métodos de inducción y deducción, del tipo aplicativo, con un diseño no experimental-transeccional de alcance descriptivo, correlacional y explicativo, según Hernández-Sampieri et al. (2014).

Para este estudio fue necesario la información correspondiente a las rocas de la zona in situ del túnel de conducción $9693 \mathrm{~m}$ y el sostenimiento instalado en el túnel de conducción de la central hidroeléctrica Cheves, los cuales se toma como base y se analizan en este estudio. A parte de ello se analizaron 108 estaciones de monitoreo geológico- geotécnico instaladas en el sostenimiento inicial del túnel de conducción de la central hidroeléctrica Cheves (figura 2).

En 49 estaciones de monitoreo geológico- geotécnico, se evidencio deformación continua en el sostenimiento inicial instalado, en estas estaciones las diferencias acumuladas son mayores a 10 milímetros, las deformaciones fueron continuas en el tiempo produciendo aumento en las medidas de convergencias.
La geología de la zona es compleja, apareciendo a lo largo del proyecto rocas vulcano-sedimentarias, volcánicas, plutónicas y formaciones metamórficas. El túnel de conducción y el complejo de Casa de Máquinas han sido excavados en roca dura. En el caso de las cavernas, éstas se encuentran en una zona estructuralmente compleja debido a la presencia de intrusiones de tonalita asociadas a juntas de cizalla subhorizontales y rocas metamórficas, investigación realizada por Sancho Moreno et al. (2015).

Las zonas inestables evidentemente se encuentran en zonas donde se ha observado eventos geológicamente complejos (fallas geológicas, diaclasas y zonas de cizalla) $y$ en las que el sostenimiento se ha deformado, generando grietas en el concreto lanzado (indicios de deformación).

La presencia de fallas geológicas rellenas de arcillas expansiva, también fueron condicionantes en el aumento de las deformaciones, la ubicación de las fallas geológicas en el túnel de conducción se muestra en la figura 3, estas fallas geológicas se formaron producto del contacto entre las cuarcitas pertenecientes a la Formación Chimú y las andesitas porfiríticas del Grupo Casma.

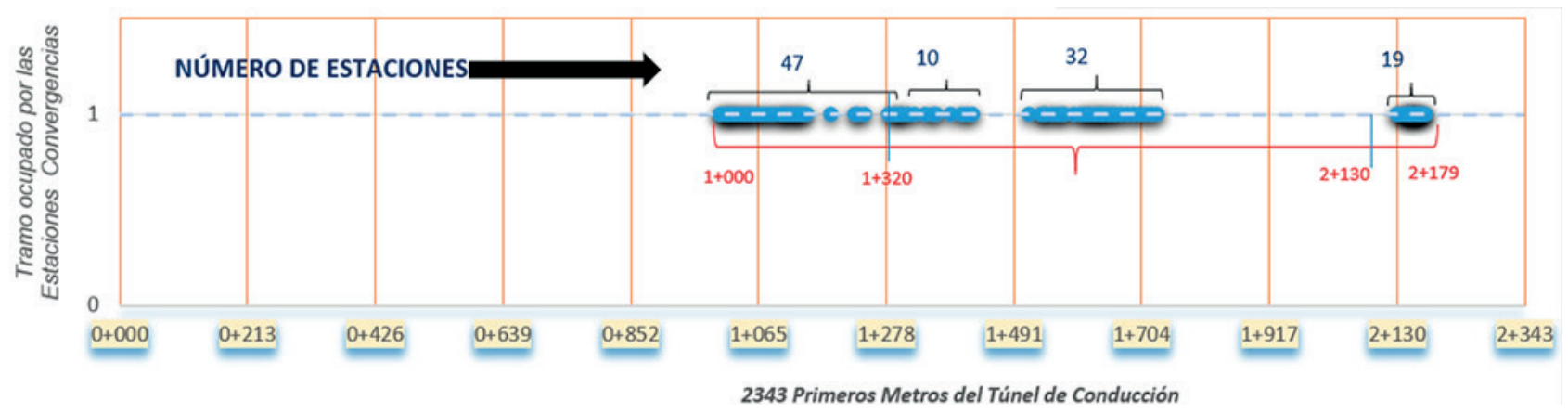

Figura 2. Número de estaciones de monitoreo geológico geotécnico en los 2343 primeros metros del túnel de conducción.
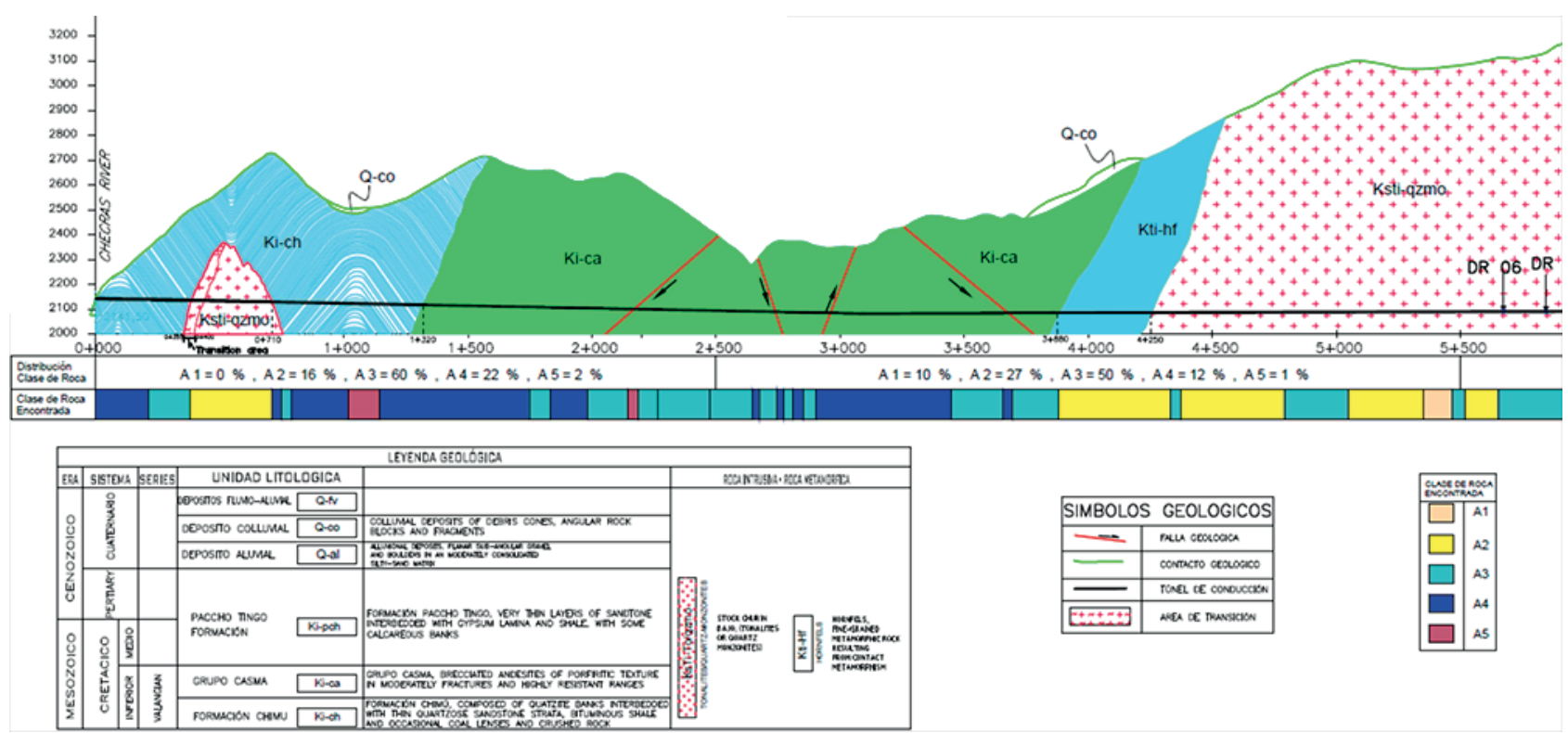

Figura 3. Perfil geológico geotécnico, tramo 0+000 - 5+000 del túnel de conducción de la central hidroeléctrica Cheves. 
Lo mencionado anteriormente ha causado deformaciones, activando las fallas geológicas al momento de la excavación subterránea, y luego de haber colocado el sostenimiento inicial, se siguió evidenciando deformaciones, plasmándose en los altos valores de las convergencias (figura 4 y 5). Con los datos de las convergencias obtenidos en campo se generó los gráficos, teniendo en cuenta las variables tiempo y desplazamiento.

\section{RESULTADOS}

\subsection{Sostenimiento inicial}

El sostenimiento inicial estuvo definido mediante clasificación geomecánica RMR Bienawski (1989), sin embargo, en el proceso constructivo también se tuvo en cuenta la evaluación geomecánica mediante el sistema Q Barton (Barton et al., 1974). Según valoración RMR la clasificación geomecánica estuvo divida en 5 tipos de roca. En el sostenimiento inicial se utiliza desde pernos CT- bolts, concreto lanzado con diferentes espesores para cada tipo de roca considerando dos tipos de dosificaciones de concreto lanzado, en el caso de la roca tipo IV se utilizó concreto lanzado con fibra, según los estándares ACI de 0.40 para Hormigón resistente al sulfato y las especificaciones técnicas del proyecto; en el caso de la roca tipo V se utilizó concreto lanzado con fibra en la capa inicial y sin fibra en la última capa o capa de revestimiento, hasta arcos reticulados para rocas de mala calidad, este sostenimiento se indica en la figura 6 .

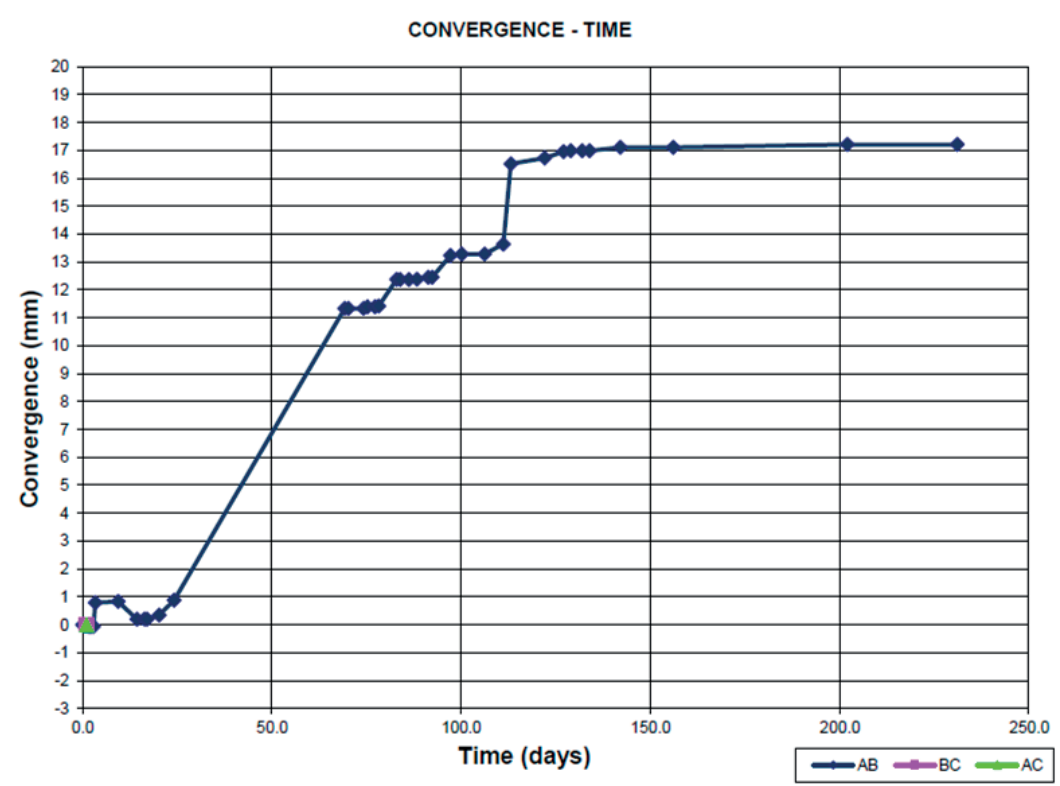

Figura 4. Grafica convergencia - tiempo, progresiva 1+005

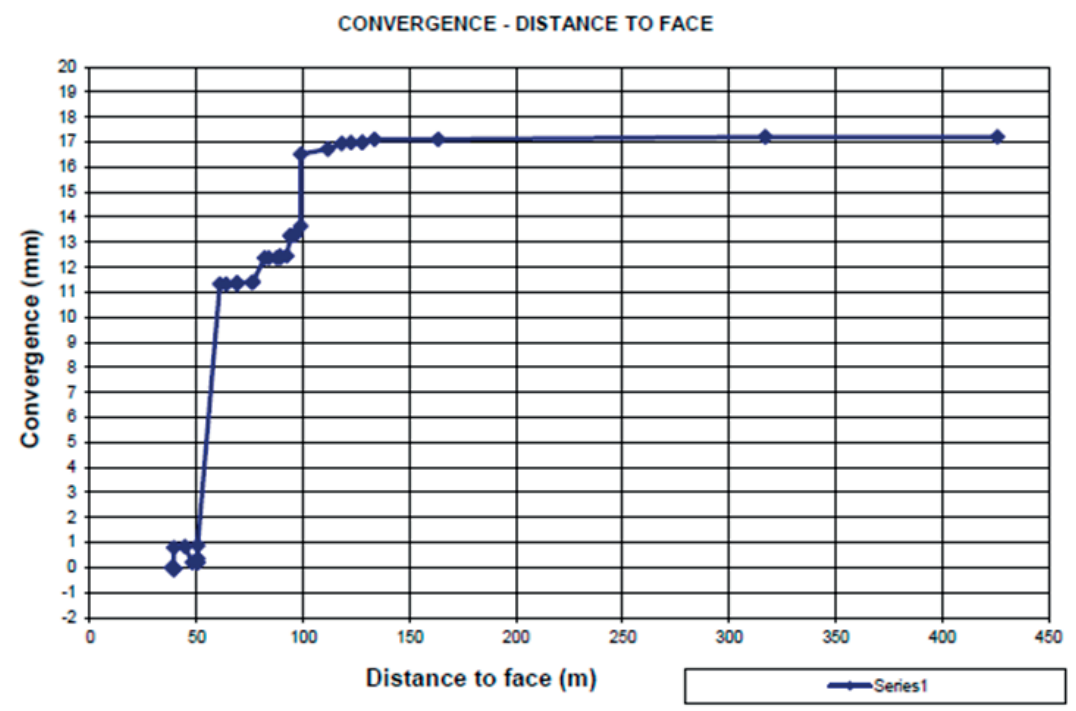

Figura 5. Grafica convergencia - distancia al frente, progresiva 1+005. 
3.2. Geomecánica de la zona donde se instaló las estaciones de monitoreo geológico - geotécnico

El túnel de conducción presenta 9693 metros de longitud, debido al proceso constructivo, y con la finalidad de avanzar en la excavación subterránea del túnel, se dividió en cuatro frentes de excavación DR-04 y DR-05 de 4500 metros y el DR-08 y DR-09 de 5193 metros de longitud. Los problemas de diseño final y complejidad geológica se dieron en el tramo comprendido desde la progresiva $1+000$ hasta la progresiva $2+200$, tramos en los cuales se estableció colocar estaciones de monitoreo geológicogeotécnico mediante convergencias.

\section{Tramo $0+951.00-1+006.40$}

Este tramo presenta un puntaje promedio RMR (Rock Mass Rating) de 54, calificado como roca tipo III. La roca es competente, pero en general está muy fracturada. Compuesta litológicamente de arenisca cuarzosa estratificada con capas de lutita negra, figura 4; en este tramo se evidencio zonas con filtraciones de agua. Desde la progresiva $0+960$ hasta la progresiva $0+970$ se evidencio pizarra negra con alto contenido de arcilla potencialmente expansiva. Entre la progresiva $0+985$ hasta la progresiva $1+000$, compuesta litológicamente de lutita con capas de carbón. La roca es competente, pero se presenta zonas sub verticales de roca triturada y arcilla negra, este tramo se encuentra seco. En la figura 7 excavación subterránea en la progresiva $0+951.20$ clasificada como tipo II.

\section{Tramo $1+006.40-1+010.20$}

Este tramo presenta un puntaje promedio RMR (Rock Mass Rating) de 37, calificado como roca tipo IV. Roca de moderada resistencia a la compresión uniaxial, presencia de diaclasas sub verticales con dirección de buzamiento de $135^{\circ}$ y buzamiento de $65^{\circ}$, este tramo se presenta totalmente

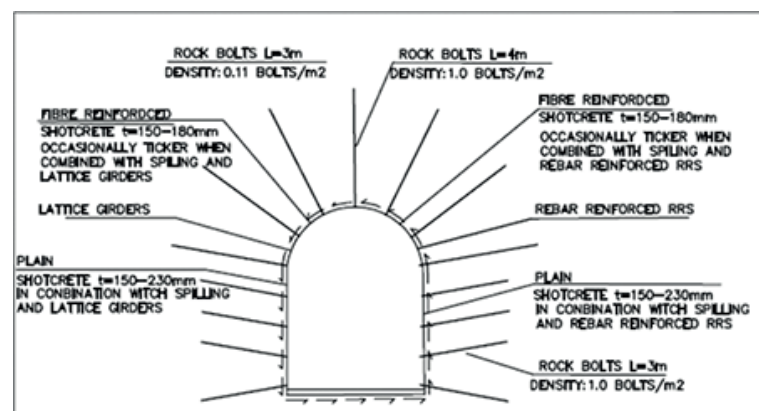

CLASS RS 4-LG CLASS RS 4-RRS

TYPICAL ROCK SUPPORT

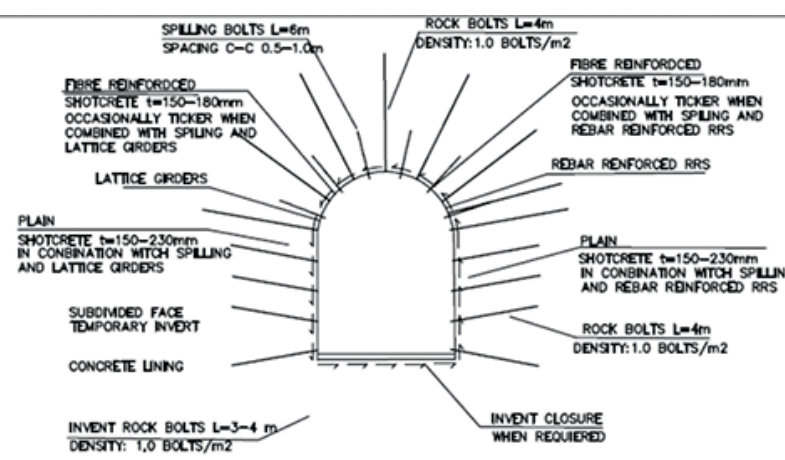

CLASS RS 5-LG CLASS RS 5-RRS

TYPICAL ROCK SUPPORT CROSS-SECTION

Figura 6. Diseño de sostenimiento para roca Tipo IV y Tipo V.

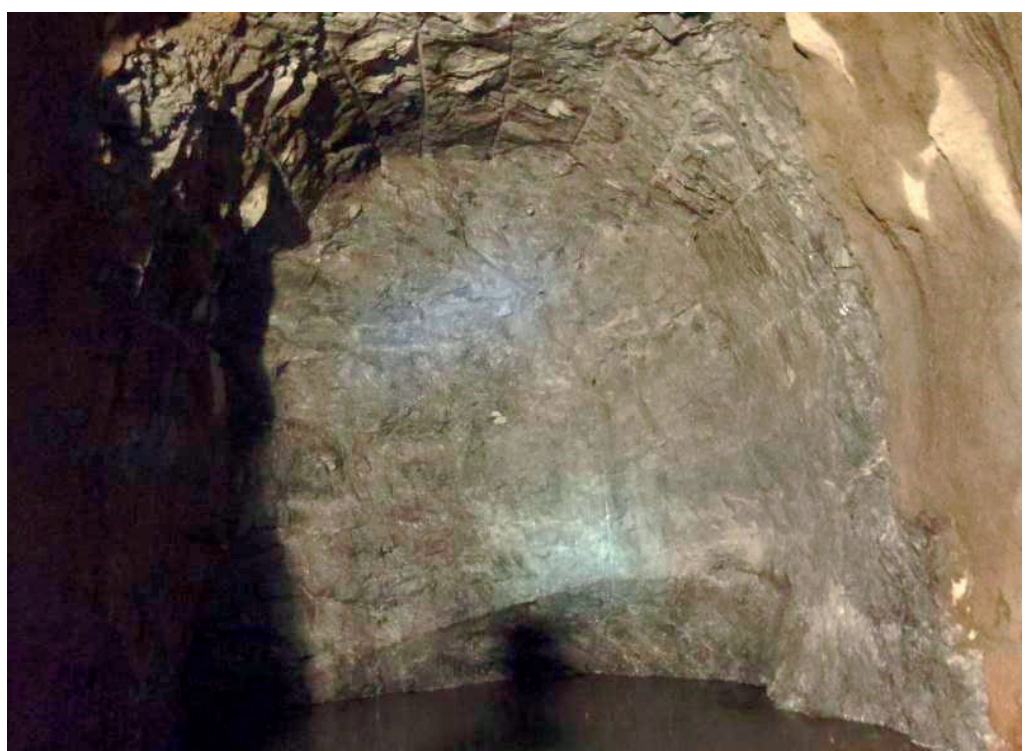

Figura 7. Progresiva 0+951.20. Roca tipo II, avance del frente de 3.1 metros, buen autosostenimonto y alta resistencia a la compensan uniaxial como propiedades de la roca. 
seco. En la figura 5 excavación subterránea en la progresiva $1+006.80$ clasificada como tipo IV.

$$
\text { Tramo } 1+010.20-1+017.40
$$

Este tramo presenta un puntaje promedio RMR (Rock Mass Rating) de 47, calificado como roca tipo III. Lentes de lutita con alto contenido de carbón, la roca es competente, pero con zonas subverticales de roca triturada y capas de pizarra. Discontinuidades con dirección de buzamiento de $10^{\circ}$ y $300^{\circ}$, buzamiento de $75^{\circ}$. Condiciones secas. Se observó agrietamiento en el concreto lanzado del sostenimiento inicial.

\section{Tramo $1+010.20-1+144.40$}

Este tramo presenta un puntaje promedio RMR (Rock Mass Rating) de 36, calificado como roca tipo IV (figura 8). Muy malas condiciones de la roca, presencia de fallas sub vertical de lutita intensamente cizallada y lentes de carbón. La orientación de las fallas es generalmente perpendicular a la alineación del túnel, las fallas presentan dirección de buzamiento $235^{\circ}$ y buzamiento de $80^{\circ}$. La roca generalmente está triturada, y de muy baja resistencia. Condiciones secas. Este tramo en general ha sido excavado mecánicamente. Altos valores de convergencias. En el tramo $1+028$ al $1+040$ se evidencio grietas en el concreto lanzado de la pared derecha y pernos adicionales instalados en la pared izquierda tomando referencia con dirección aguas abajo.

En el tramo $1+055$ al $1+092$, presenta un puntaje promedio RMR (Rock Mass Rating) de 40, calificado como roca Tipo IV; el macizo rocoso presenta condiciones de roca extremadamente malas. Zona de falla sub vertical con lutita laminada y negra intensamente cizallada y alto contenido de arcilla negra y gris, la falla presenta una dirección de buzamiento de $235^{\circ}$ y buzamiento de $40^{\circ}$. La orientación de la junta es generalmente perpendicular a la alineación del túnel. La roca generalmente está triturada y los fragmentos de resistencia extremadamente baja. Condiciones secas. Tramo con excavación mecánica. Altos valores de convergencias. Presencia de grietas menores en el concreto lanzado de la pared izquierda tomando referencia con dirección aguas abajo. Colapso del frente y sobreexcavación en bóveda al momento de la excavación en la progresiva $1+055$, volumen colapsado de unos $75 \mathrm{~m}^{3}$ de la parte superior del frente.

Tramo $1+092.70$ al $1+130$, presenta un puntaje promedio RMR (Rock Mass Rating) de 39, calificado como roca Tipo IV, condiciones de roca de regular a mala. Zona de falla sub vertical con lutita laminada, zona intensamente cizallada, con lentes de arcilla negra. Las estructuras geológicas se encuentran generalmente perpendicular al eje del túnel, pero el buzamiento varía debido al micro plegado. Con dirección de buzamiento de $100^{\circ} \mathrm{y}$ buzamiento $80^{\circ} \mathrm{y}$ dirección de buzamiento $280^{\circ} \mathrm{y}$ buzamiento $75^{\circ}$. La roca presenta muy baja resistencia a la compresión uniaxial. Condiciones secas para este tramo. Respecto a los tramos anteriores la estabilidad de la sección mejora en los últimos $10 \mathrm{~m}$ de la sección. Tramo Excavado mecánicamente. Altos valores de convergencias. Se visualiza indicios de deformación del sostenimiento inicial debido a desprendimiento del concreto lanzado.

En el tramo $1+130$ al $1+144$, presenta un puntaje promedio RMR (Rock Mass Rating) de 40, calificado como roca Tipo IV Arenisca finamente estratificada intercalada con pizarra laminada, con inclusiones de lentes de arcilla negra. Rocas en muy malas condiciones, intensamente cizalladas. Resistencia baja a muy baja. Goteo de agua de algunas zonas de cizallamiento. La roca se vuelve demasiado dura para la excavación mecánica. Altos valores de convergencias. Alto contenido de arcilla expansiva.

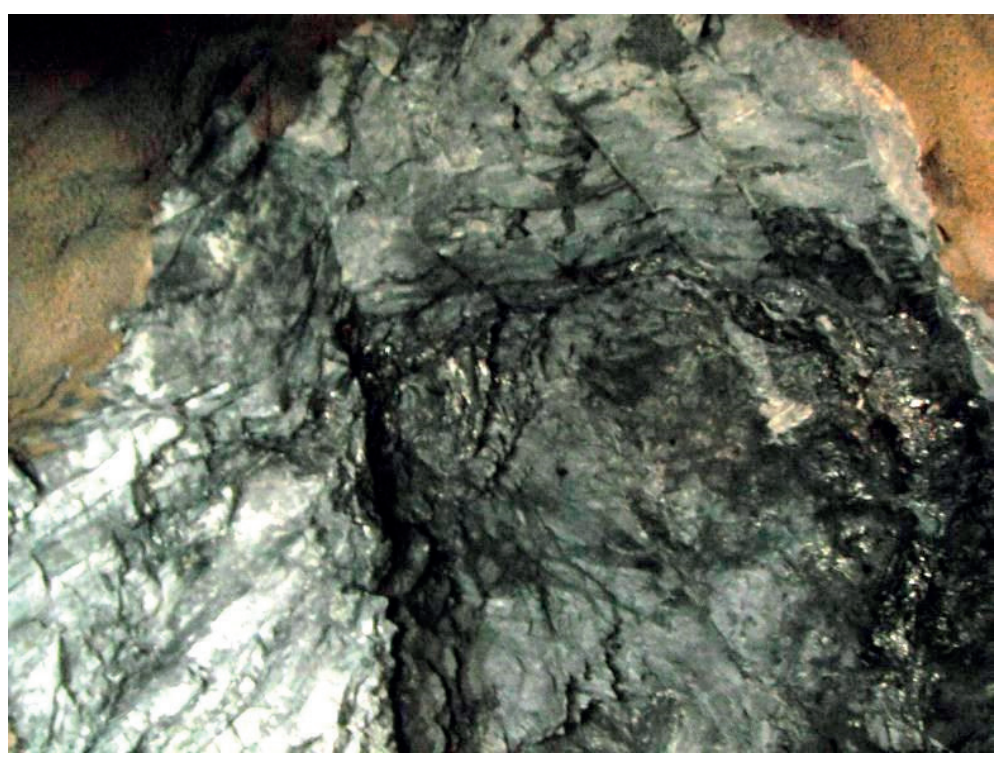

Figura 8. Progresiva 1+006.80. La clasificación geomecánica evidencia roca tipo IV, presencia de carbón, las fracturas en la roca se encuentran rellenas de arcilla, producto de la descomposición del carbón. 
Tramo $2+144.00-2+156.00$

Este tramo presenta un puntaje promedio RMR (Rock Mass Rating) de 56, calificado como roca tipo III. El avance promedio hasta este tramo fue de 3.5 metros; se evidencia limos y óxidos en la cara del frente del túnel. Presencia de alta densidad de juntas, con dirección de buzamiento $240^{\circ}$ y buzamiento $80^{\circ}$. Condiciones secas para este tramo, pero se evidencio presencia de óxidos.

Tramo $2+156.00-2+182.20$

Este tramo presenta un puntaje promedio RMR (Rock Mass Rating) de 38, calificado como roca tipo IV. Zona compuesta de falla geológica, la roca andesita se encuentra muy alterada, se evidencia zonas de arcilla expansiva y clorita alterada, la falla geológica presenta una dirección de buzamiento de $10^{\circ}$ y buzamiento de $20^{\circ}-30^{\circ}$. La roca es de tan baja autoestabilidad que la excavación es mecánica, dejando un volumen de roca en la parte central baja del frente con el fin de autosostener el frente de avance y la bóveda, el avance promedio fue de 0.9 metros. En la progresiva $2+168$ se evidenció presencia de agua en la parte alta del frente de avance.

\section{Tramo $2+182.80-2+190.00$}

Este tramo presenta un puntaje promedio RMR (Rock Mass Rating) de 57, calificado como roca tipo III. Andesita de moderada a buena resistencia de compresión uniaxial, baja a modera alteración, las juntas se encuentras rellenas de cuarzo, presencia de óxidos en escasas cantidades.

\subsection{Fisuras en el concreto lanzado del sostenimiento inicial}

Para este artículo se toma en cuenta dos figuras representativas figura 9 y figura 10, las medidas y ubicación del total de fisuras evidenciadas se indica en la Tabla 1,

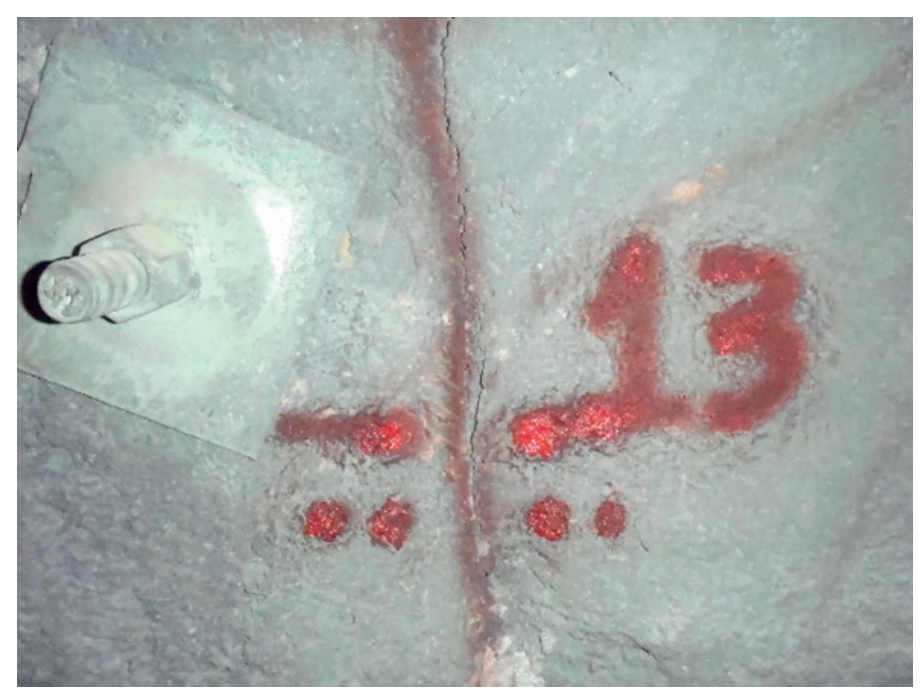

Figura 9. Progresiva 1+107. Se evidencia fisura vertical en el concreto lanzado. Hastial izquierdo con dirección hacia aguas abajo.

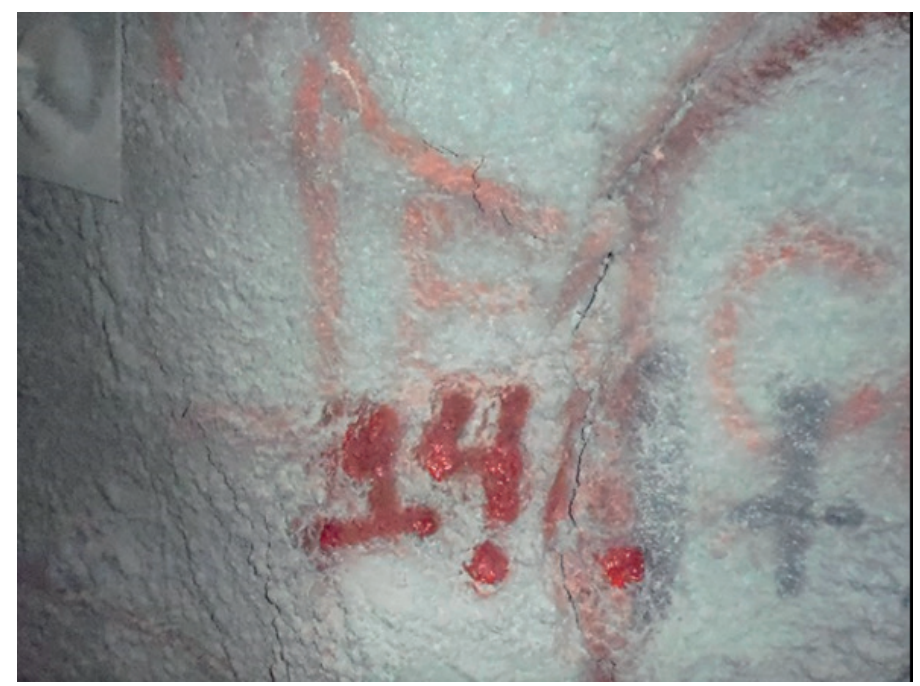

Figura 10. Progresiva 1+105. Se evidencia fisura vertical en el concreto lanzado. Hastial izquierdo con dirección hacia aguas abajo. 
Tabla 1. Registro de las fisuras en el concreto lanzado del túnel de conducción

\begin{tabular}{|c|c|c|c|c|c|c|c|c|}
\hline \multirow[b]{2}{*}{$\begin{array}{c}\text { Fisuras } \\
\text { Progresiva }\end{array}$} & \multirow[b]{2}{*}{$\mathrm{N}^{\circ}$ de fisura } & \multicolumn{3}{|c|}{ Posición } & \multicolumn{4}{|c|}{ Fecha de la medida y valor del espesor de la fisura } \\
\hline & & $\begin{array}{c}\text { Hastial } \\
\text { Izquierdo }\end{array}$ & Bóveda & $\begin{array}{l}\text { Hastial } \\
\text { Derecho }\end{array}$ & $\begin{array}{c}20 / 10 / 2013 \\
(\mathrm{~mm})\end{array}$ & $\begin{array}{c}29 / 11 / 2013 \\
(\mathrm{~mm})\end{array}$ & $\begin{array}{c}2 / 03 / 2014 \\
(\mathrm{~mm})\end{array}$ & $\begin{array}{c}3 / 03 / 2014 \\
(\mathrm{~mm})\end{array}$ \\
\hline 1023.5 & 1 & $x$ & & & 1 & - & - & - \\
\hline 1028.5 & 2 & & & $x$ & 1.5 & - & - & - \\
\hline 1030.5 & 3 & & & $x$ & 1 & - & - & - \\
\hline 1031.5 & 4 & & & $x$ & 1 & - & - & - \\
\hline 1034.5 & 5 & & & $x$ & 1 & - & - & - \\
\hline 1037.0 & 6 & & & $x$ & 2 & - & - & - \\
\hline 1038.5 & 7 & & & $x$ & 1 & - & - & - \\
\hline 1042.0 & 8 & $x$ & & & 2 & - & - & - \\
\hline 1068.5 & 9 & & & $x$ & 2 & - & - & - \\
\hline 1078.0 & 10 & $x$ & & & 2.5 & - & - & - \\
\hline 1081.0 & 11 & $x$ & & & 3 & - & - & - \\
\hline 1093.0 & 12 & & & $x$ & 1 & - & - & - \\
\hline 1107.0 & 13 & $x$ & & & 3 & - & - & - \\
\hline 1105.5 & 14 & $x$ & & & 10 & - & - & - \\
\hline 1109.0 & 15 & $x$ & & & 2 & - & - & - \\
\hline 1121.0 & 16 & & & $x$ & 3 & - & - & - \\
\hline 1125.0 & 17 & $x$ & & & 1 & - & - & - \\
\hline 1126.5 & 18 & $x$ & & & 2 & - & - & - \\
\hline 1129.0 & 19 & $x$ & & & 0 & - & - & - \\
\hline 1129.0 & 20 & & & $x$ & 2 & - & - & - \\
\hline 1135.0 & 21 & $x$ & & & 1 & - & - & - \\
\hline 1144.0 & 22 & & & $x$ & 0 & - & - & - \\
\hline 1149.5 & 23 & $x$ & & & 3 & - & - & - \\
\hline 1151.0 & 24 & & & $x$ & 4 & - & - & - \\
\hline 1338.0 & 1 & & & $x$ & - & - & 0.5 & - \\
\hline 2126.0 & $6^{\mathrm{a}}$ & $x$ & & & - & 0 & - & - \\
\hline 2128.5 & $7^{\mathrm{a}}$ & $x$ & & & - & 0 & - & - \\
\hline 2182.0 & 16 & $x$ & & & - & - & 1 & - \\
\hline 2182.0 & $16^{a}$ & & & $x$ & - & - & 1 & - \\
\hline 2183.0 & 15 & $x$ & & & - & - & 0.5 & - \\
\hline 2183.0 & $17^{a}$ & & & $x$ & - & - & 1 & - \\
\hline 2184.0 & $18^{a}$ & & & $x$ & - & - & 1 & - \\
\hline 2185.0 & 14 & & & $x$ & - & - & 0.5 & - \\
\hline 2186.0 & 13 & $x$ & & & - & - & 1.5 & - \\
\hline 2188.0 & $19^{a}$ & $x$ & & & - & - & 0.5 & - \\
\hline 2190.0 & $22^{\mathrm{a}}$ & & & $x$ & - & - & 1 & - \\
\hline 2190.0 & $23^{\mathrm{a}}$ & $x$ & & & - & - & 0.5 & - \\
\hline
\end{tabular}

estas fisuras reflejan la instabilidad del sostenimiento del túnel de conducción, debido a ello se registró por progresiva la ubicación de las fisuras encontradas en el concreto lanzado del sostenimiento inicial del túnel de conducción. Esto se consiguió mediante el mapeo de las fisuras del concreto lanzado. En la figura 9 se muestra las fisuras formadas en la progresiva $1+006.80$ del hastial derecho. La mayor densidad de fisuras se evidenció entre las progresivas $1+000$ a $1+728$ y el tramo comprendido entre las progresivas $2+130$ al $2+179$.

\subsection{Estaciones de monitoreo geológico - geotécnico}

Luego de instalar el sostenimiento inicial se instalaron estaciones de monitoreo geológico - geotécnico en zonas donde se evidencio indicios de inestabilidad del sostenimiento inicial (Rodríguez Cruzado, 2018), 
reflejados en fisuras y desprendimientos del concreto lanzado. En total se instalaron 108 estaciones de monitoreo geológico-geotécnico. Una estación de monitoreo geológico - geotécnico consta de 3 hitos en la sección del túnel, 1 hito se ubica en la parte central de la bóveda y 1 hito en la parte intermedia del hastial izquierdo y otro en la parte intermedia del hastial derecho, esto se indica en la figura 11.

La medida de los hitos se realizó mediante huincha extensométrica, para el registro de las medidas de convergencias se tuvo en cuenta la fecha de instalación de los hitos y la distancia al frente de avance al momento de realizar la lectura de las convergencias. Luego de instalar el sostenimiento inicial, las lecturas de convergencias fueron altas en 49 estaciones de monitoreo. En la figura
12 se muestra el grafico de la estación de convergencia de la progresiva $1+015$, indicando deformaciones altas en tiempo-días.

En la figura 13 se muestra el grafico de la estación de convergencia de la progresiva $1+035$, indicando deformaciones altas en tiempo-días.

En la figura 14 se muestra el gráfico de la estación de convergencia de la progresiva $2+150$, indicando deformaciones altas en tiempo-días.

\subsection{Sostenimiento final del túnel de conducción}

De las 108 estaciones de monitoreo geológico- geotécnico, en 49 estaciones se registraron valores altos de convergencias con diferencias acumuladas mayores a 10

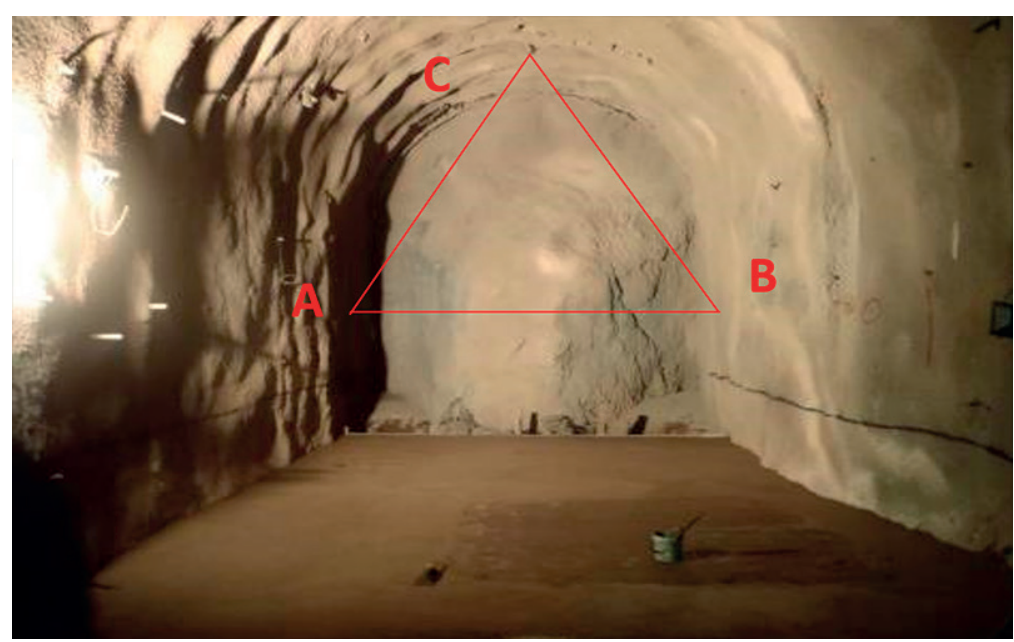

Figura 11. Ubicación de los hitos; la línea roja indica la medida a realizar con la huincha extensométrica; en la foto se muestra la progresiva 1+055.00 del túnel de conducción, el frente de avance tiene una dirección hacia aguas abajo.

Fuente: Elaboración propia.

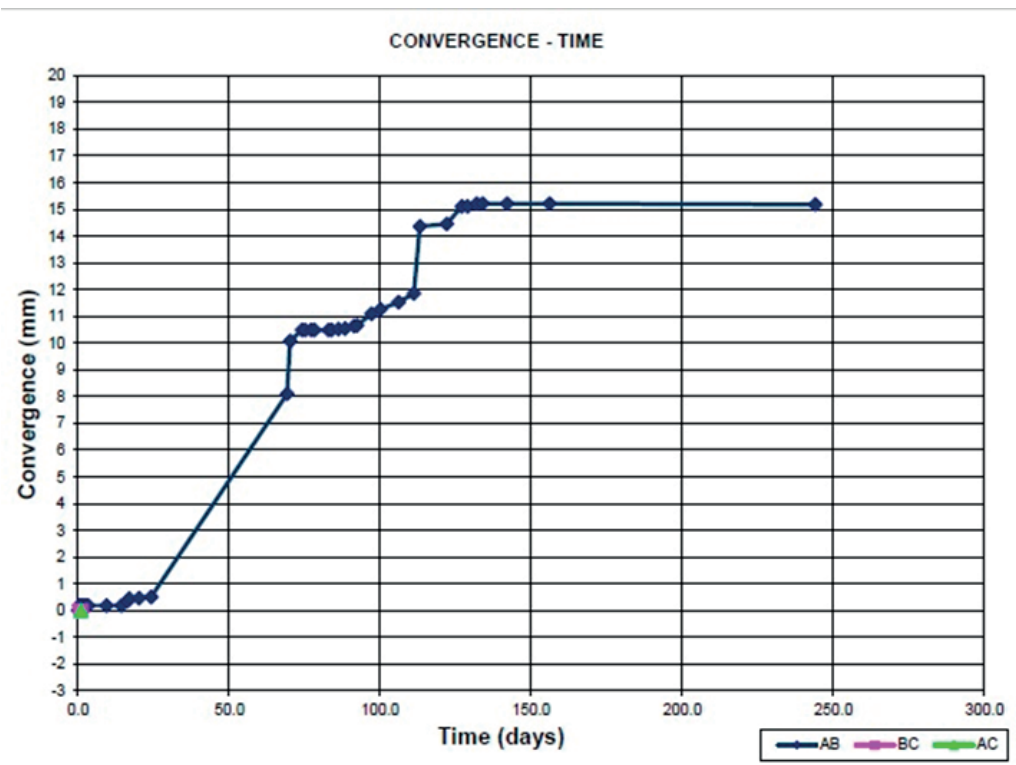

Figura 12. Gráfico de la estación de convergencia de la progresiva 1+015, indicando deformaciones altas. 


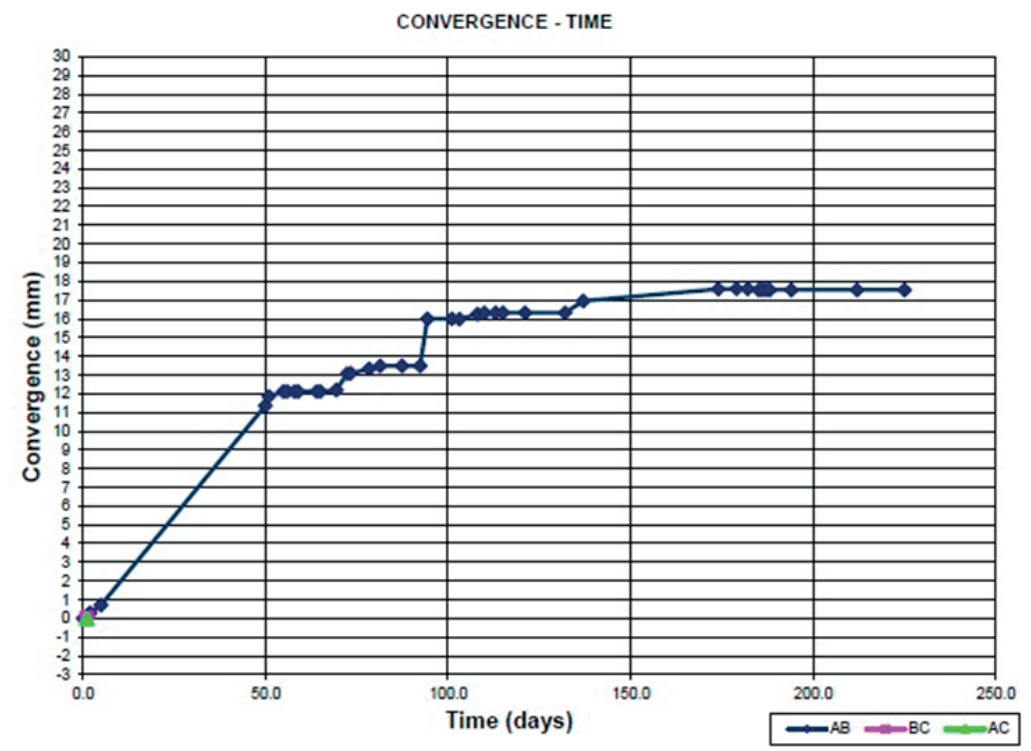

Figura 13. Gráfico de la estación de convergencia de la progresiva 1+035, indicando deformaciones altas.

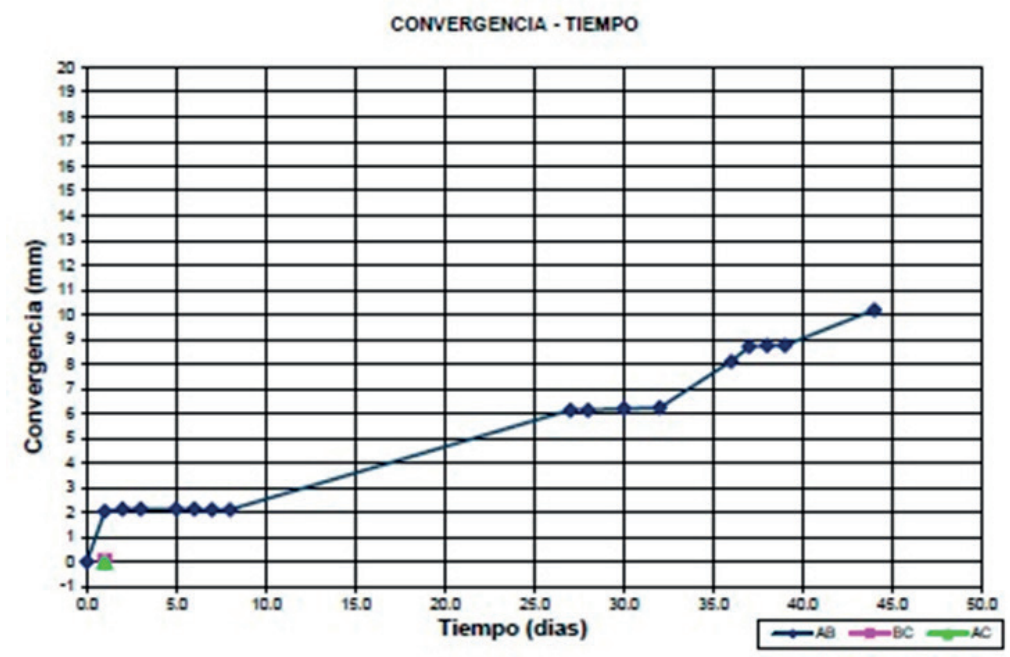

Figura 14. Gráfico de la estación de convergencia de la progresiva 2+150, indicando deformaciones altas.

milímetros, no existe norma técnica o especificación que indique el rango para convergencias, por lo que se tomó en cuenta el valor contractual del proyecto, a ello sumado la evidencia de fisuras en el concreto lanzado, se vio por conveniente instalar y reforzar con sostenimiento complejo consistente en concreto armado entre los hastiales y la bóveda del túnel de conducción, este sostenimiento es denominado "concrete lining", como muestra la figura 15.

Luego de haber instalado el sostenimiento pesado entre los tramos $1+015-1+325$ y tramo $2+130-2+179$, se instaló 09 estaciones de monitoreo geológico- geotécnico, realizando las lecturas y posterior graficas teniendo como resultado la estabilidad de las convergencias en dichos tramos con valores de diferencia acumulada de 0.00. Las lecturas de convergencias fueron calculadas y replanteadas utilizando el software Excel. El resumen de las convergencias posterior al sostenimiento final se presenta en la Tabla 2.

El modelo que se analizó muestra una geología tales como intrusivos, generando esfuerzos de compresión entre el volcánico del Grupo Casma, así mismo para analizar este modelo he tenido que realizar un modelo geológico (ver figura 16 y figura 17), perfil longitudinal de la geología del proyecto, una vista espacial que se da dentro del mismo perfil mencionado, y haber leído todo el proyecto que realizo la empresa antes de la ejecución de la obra en la cual yo participe desde mediados del 2013 hasta el final del año 2014, realizando trabajos de supervisión en el área de geología.

Por otra parte, se tiene en cuenta la determinación de la cantidad de estaciones de monitoreo, la cuantificación 


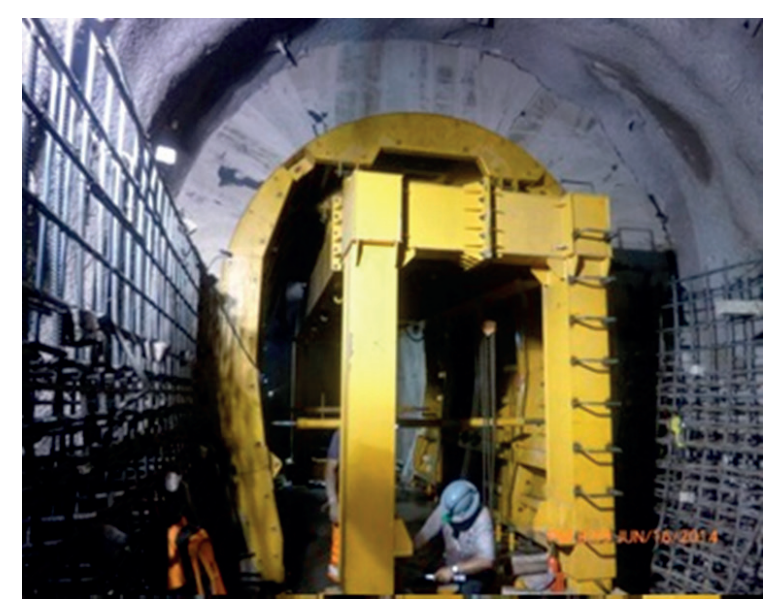

Figura 15. Sostenimiento complejo consistente en concreto armado entre los hastiales y la bóveda del túnel de conducción.

Tabla 2. Resumen de las medidas de convergencias posterior al sostenimiento final del túnel de conducción

\begin{tabular}{|c|c|c|c|c|c|c|c|c|c|c|c|}
\hline \multirow{2}{*}{$\begin{array}{l}\text { Progresiva } \\
\text { Estación }\end{array}$} & \multirow{2}{*}{$\begin{array}{l}\text { Sostenimiento } \\
\text { Inicial }\end{array}$} & \multicolumn{2}{|c|}{ cha de instalación } & \multicolumn{2}{|c|}{ Primera Medición } & \multicolumn{2}{|c|}{ Última Medición } & \multirow{2}{*}{$\begin{array}{c}a b \\
\text { Dif Acum }\end{array}$} & \multirow{2}{*}{$\begin{array}{c}V \\
\text { (mm/dia) }\end{array}$} & \multirow{2}{*}{ Estatus } & \multirow{2}{*}{$\begin{array}{l}\text { Observaciones } \\
\text { Note: e: Estable; i: } \\
\text { Inestable; } \\
\text { t: tendencia } \\
\text { estabilizar. }\end{array}$} \\
\hline & & 그. & & Fecha & Lectura & Fecha & Lectura & & & & \\
\hline $1+030.00$ & 16/02/2012 & $29 / 09 / 2014$ & $15 / 10 / 2014$ & 16/10/2014 & 3885.1 & 25/10/2014 & 3885.1 & 0 & 0 & e & Estable \\
\hline $1+080.00$ & $25 / 05 / 2012$ & $29 / 09 / 2014$ & $15 / 10 / 2014$ & $16 / 10 / 2014$ & 3884.45 & $25 / 10 / 2014$ & 3884.45 & 0 & 0 & e & Estable \\
\hline $1+121.00$ & 11/07/2012 & 29/09/2014 & $15 / 10 / 2014$ & $16 / 10 / 2014$ & 3885.2 & 25/10/2014 & 3885.2 & 0 & 0 & e & Estable \\
\hline $1+232.00$ & 28/08/2012 & $29 / 09 / 2014$ & $15 / 10 / 2014$ & $16 / 10 / 2014$ & 3884.15 & $25 / 10 / 2014$ & 3884.15 & 0 & 0 & e & Estable \\
\hline $1+312.00$ & $14 / 09 / 2012$ & 29/09/2014 & $15 / 10 / 2014$ & $16 / 10 / 2014$ & 3885.2 & $25 / 10 / 2014$ & 3885.2 & 0 & 0 & e & Estable \\
\hline $2+145.00$ & $7 / 11 / 2013$ & 22/07/2014 & $15 / 10 / 2014$ & $16 / 10 / 2014$ & 3885.1 & $26 / 10 / 2014$ & 3885.1 & 0 & 0 & e & Estable \\
\hline $2+150.00$ & $7 / 11 / 2013$ & $22 / 07 / 2014$ & $15 / 10 / 2014$ & $16 / 10 / 2014$ & 3884.5 & $26 / 10 / 2014$ & 3884.5 & 0 & 0 & e & Estable \\
\hline $2+153.00$ & $7 / 11 / 2013$ & $22 / 07 / 2014$ & $15 / 10 / 2014$ & $16 / 10 / 2014$ & 3885.25 & $26 / 10 / 2014$ & 3885.25 & 0 & 0 & e & Estable \\
\hline $2+165.00$ & $14 / 11 / 2013$ & $22 / 07 / 2014$ & $15 / 10 / 2014$ & $16 / 10 / 2014$ & 3884.5 & $26 / 10 / 2014$ & 3884.5 & 0 & 0 & e & Estable \\
\hline
\end{tabular}

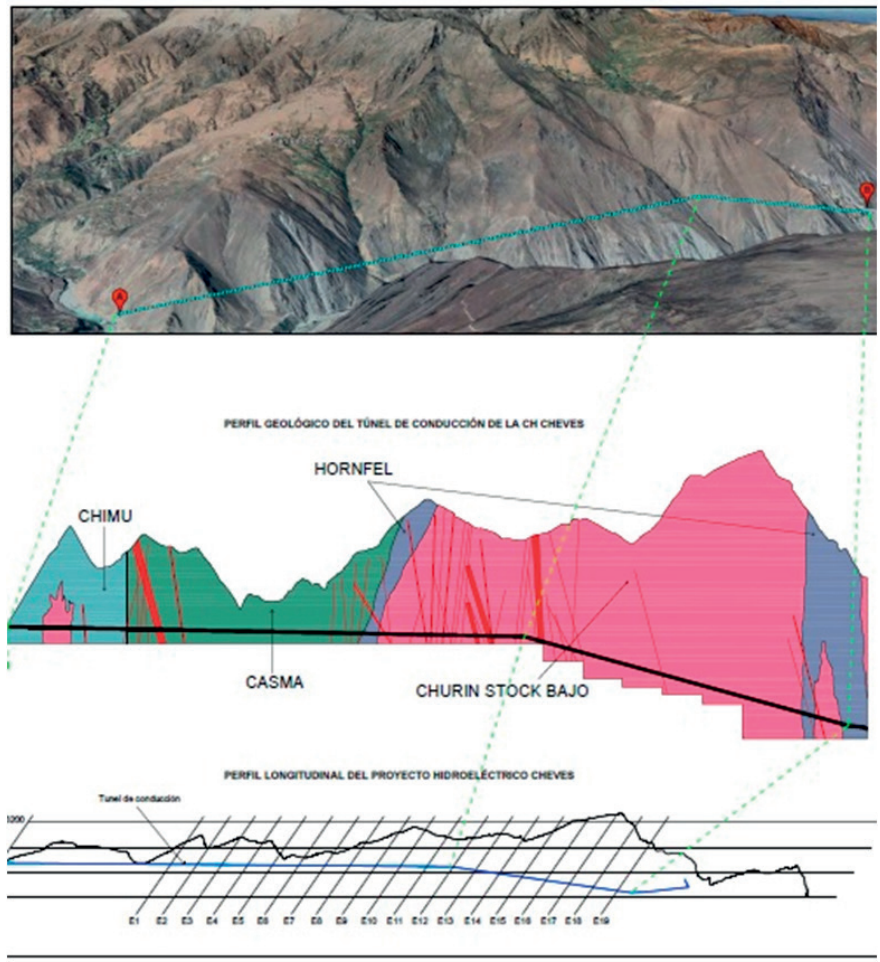

Figura 16. Modelo Geológico. 
de la deformación del sostenimiento y la cuantificación del tiempo de deformación del sostenimiento, como muestra la figura 18 .

En la figura 19 muestro el flujograma del Modelo de Monitoreo Geológico - Geotécnico mediante Convergencias, que se pudo deducir de esta investigación del proyecto Central Hidroeléctrica Cheves.

\section{CONCLUSIONES}

- Las convergencias vienen siendo aplicadas a muchos proyectos de excavación subterránea, sin embargo, para evitar colapsos o inestabilidades en sostenimientos, se puede aplicar el modelo geológico-geotécnico analizado; el ambiente geológico que analiza este modelo se fundamenta en roca tipo III, IV y tipo V.
- De las 108 estaciones de monitoreo geológico geotécnico, en 49 estaciones de monitoreo geológico geotécnico se evidencio convergencias, producto de la inestabilidad del sostenimiento inicial; dicha inestabilidad se plasmaron en deformaciones y grietas en el concreto lanzado, las deformaciones evidenciadas fueron continuas en el tiempo y en el espacio, sobrepasando los 10 milímetros de convergencias en las secciones analizadas, por ello se decidió colocar un sostenimiento más pesado y complejo denominado concrete lining.

\section{AGRADECIMIENTOS}

A la Escuela Académico Profesional de Ingeniería Geológica de la Universidad Nacional Mayor de San Marcos. En especial al Mg. Víctor Tolentino Y., al Dr.

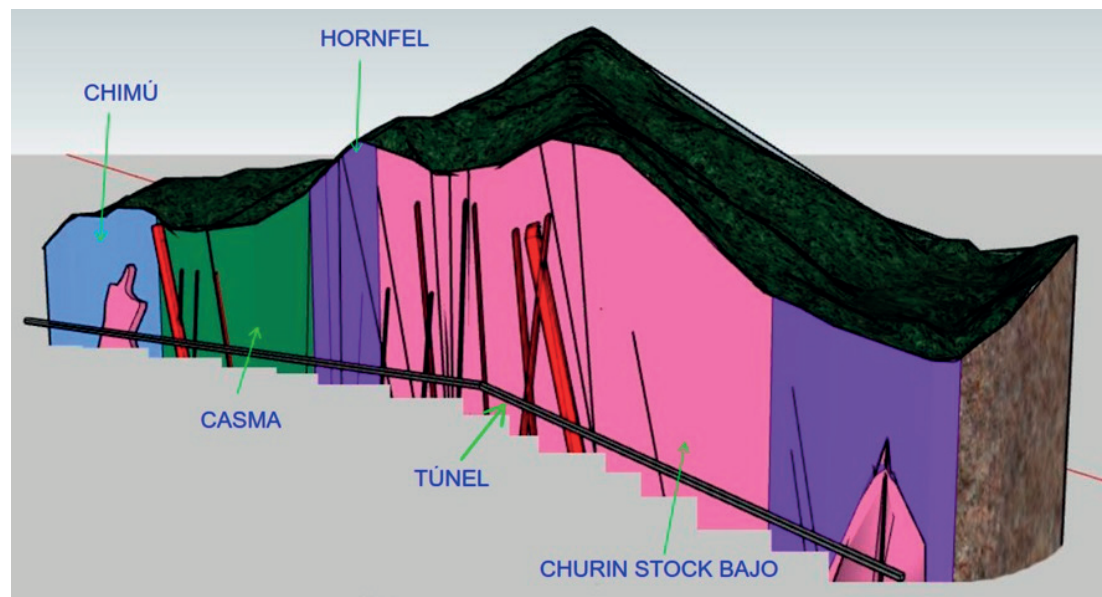

Figura 17. Modelo Geológico.

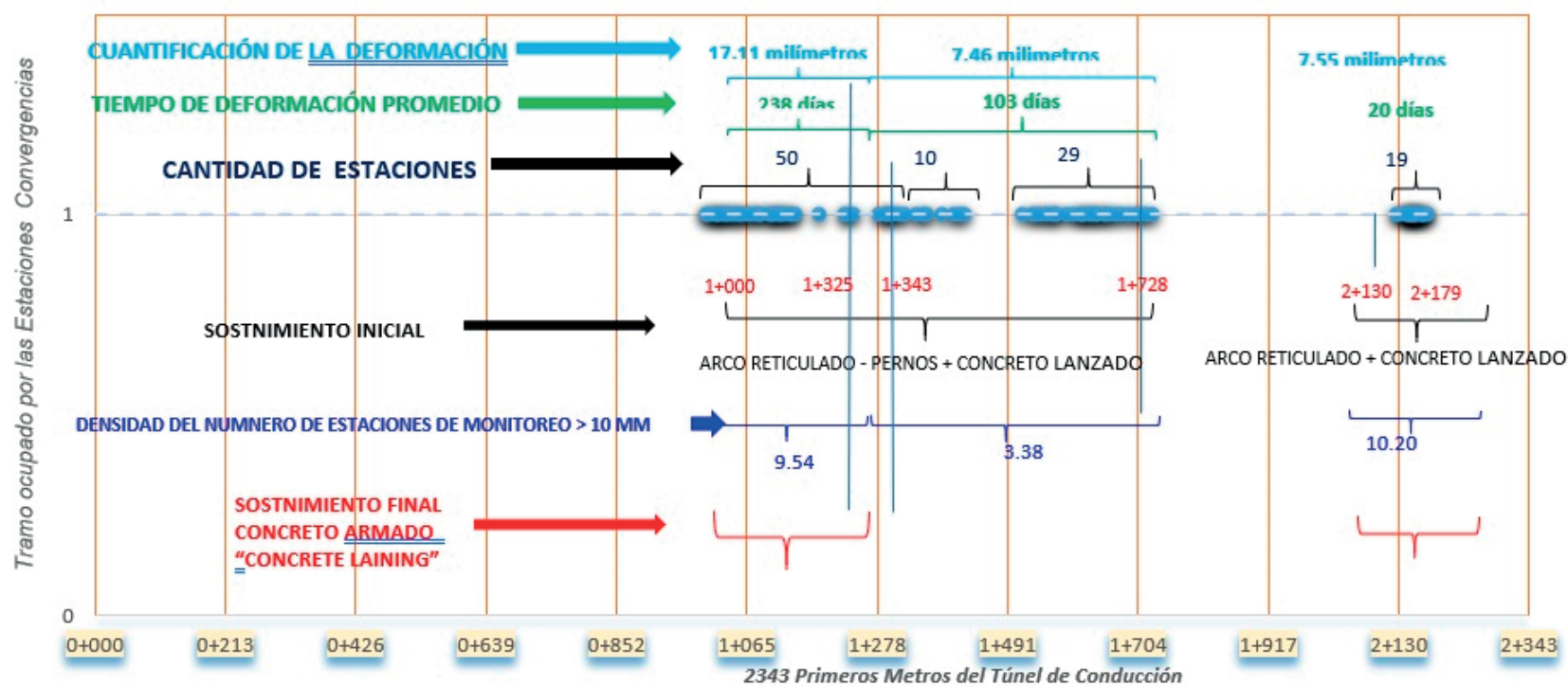

Figura 18. Cuantificación de la deformación del sostenimiento y la cuantificación del tiempo de deformación del sostenimiento. 


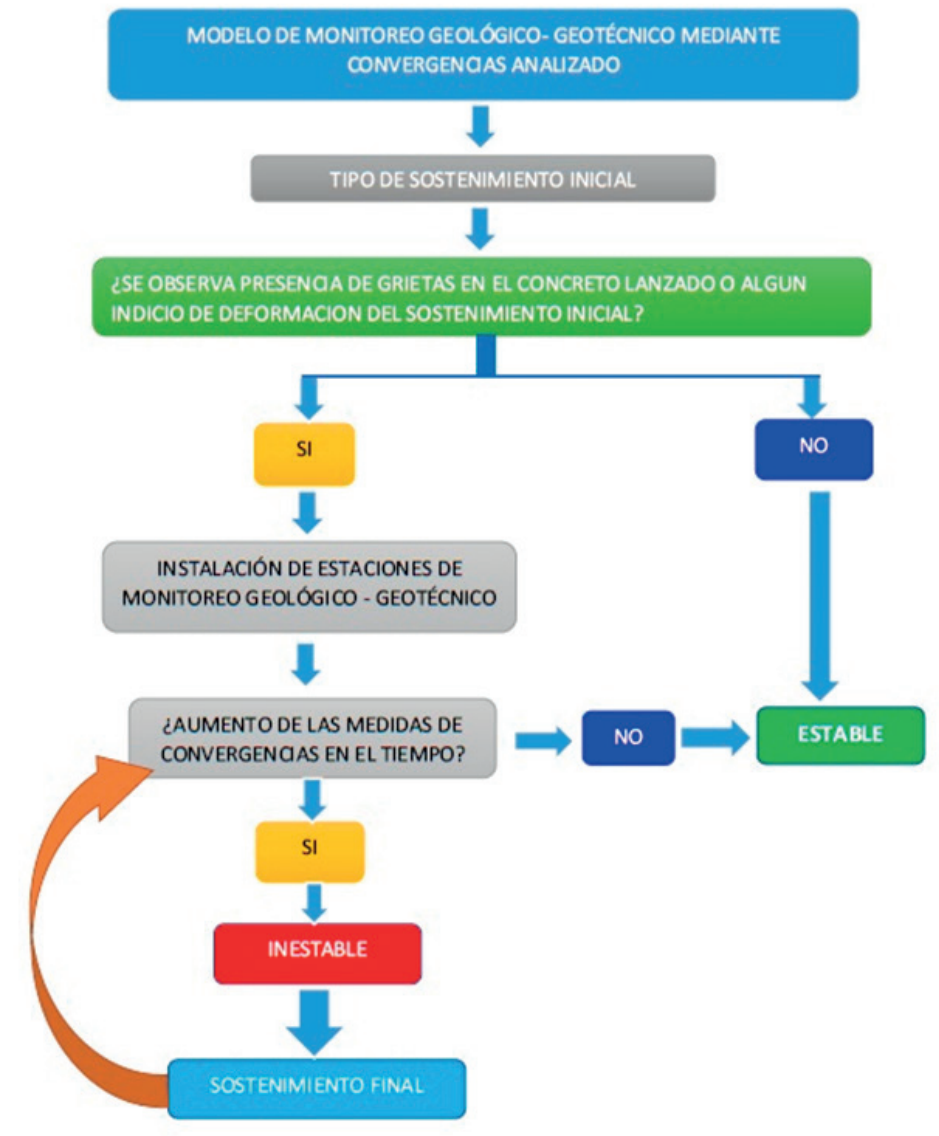

Figura 19. Flujograma del modelo de monitoreo geológico - geotécnico mediante convergencias.

Tomás Ezequiel Gallarday Bocanegra, por sus consejos y apreciaciones para mejorar este estudio presentado.

\section{REFERENCIAS}

Barton, N., Lien, R., \& Lunde, J. (1974). ENGINEERING CLASSIFICATION OF ROCK MASSES FOR THE DESIGN OF TUNNEL SUPPORT. Norg Geotek Inst, Publ, 106. https://doi.org/10.1016/0148-9062(75)91319-4

Bieniawski, Z. T. (1989). Engineering Rock Mass Classifications. Pennsylvania, USA John Wiley \& Sons. pp. 45-60 https://books.google.com.pe/books?id=pejDUvjwPdMC $\& 1 \mathrm{pg}=\mathrm{PP} 13 \& \mathrm{dq}=$ Bieniawski\%2C $\% 20 \mathrm{Z} . \% 20 \mathrm{~T} . \% 20$ (1989).\%20Engineering\%20Rock\%20Mass\%20 Classifications.\%20Pennsylvania\%2C\%20USA\%20 John $\% 20$ Wiley $\% 20 \% 26 \% 20$ Sons.\%20pp.\%20 $45-60 \& \operatorname{lr} \& \mathrm{hl}=$ es\&pg $=\mathrm{PP} 1 \# \mathrm{v}=$ onepage $\& \mathrm{q} \& \mathrm{f}=$ true

Cobbing, E. J. (1973). IMGEMMET BOLETIN NO. A26: Geología de los cuadrángulos de Barranca, Ámbar, Oyón, Huacho, Huaral y Canta 22-h, 22-i, 22-j, 23-h, 23-i, 23-j. In IMGEMMET REPORTS. https://repositorio.ingemmet.gob. pe/handle/20.500.12544/144
Hernández-Sampieri, R., Fernández Collado, C., \& Baptista Lucio, M. del P. (2014). Metodología de la investigación (Sexta Edic). McGraw-Hill Interamericana. https://www. uca.ac.cr/wp-content/uploads/2017/10/Investigacion.pdf

Rodríguez Cruzado, S. R. (2018). Método de investigación geológico-geotécnico para el análisis de inestabilidad de laderas por deslizamientos zona Ronquillo-Corisorgona Cajamarca-Perú. Revista Del Instituto de Investigación de La Facultad de Ingeniería Geológica, Minera, Metalurgica y Geográfica, 20(39), 167-174. https://cybertesis.unmsm. edu.pe/handle/20.500.12672/5617

Sancho Moreno, M., Boisán González, M., Veyrat Marqués, S., \& Galera Fernández, J. M. (2015). Construcción de túneles profundos para aprovechamientos hidráulicos. Central hidroeléctrica Cheves (Perú). Revista de Obras Publicas, 162(3568), 79-96. https://subterra-ing.com/wp-content/ uploads/2018/11/2015.-ROP-septiembre_3568_07.pdf 